Published in final edited form as:

Chem Res Toxicol. 2016 August 15; 29(8): 1279-1281. doi:10.1021/acs.chemrestox.6b00210.

\title{
Assessment of Protein Binding of 5-Hydroxythalidomide Bioactivated in Humanized Mice with Human P450 3A- chromosome or Hepatocytes by Two-dimensional Electrophoresis/Accelerator Mass Spectrometry
}

\author{
Hiroshi Yamazaki ${ }^{\dagger,}$, Hiroshi Suemizu $\ddagger$, Yasuhiro Kazuki§, Ken Oofusa", Shunji \\ Kuribayashi $^{\perp}$, Makiko Shimizu $^{\dagger}$, Shinichi Ninomiya ${ }^{\sharp}$, Toru Horie ${ }^{\complement}$, Norio Shibata I, and F. \\ Peter Guengerich' \\ †Showa Pharmaceutical University, Machida, Tokyo 194-8543, Japan \\ ¥Central Institute for Experimental Animals, Kawasaki-ku, Kawasaki 210-0821, Japan \\ $\S$ Graduate School of Medical Science, Tottori University, Yonago, Tottori 683-8503, Japan \\ "Idea Consultants Inc., Suminoe-ku, Osaka 559-8519, Japan \\ ${ }^{\perp}$ Otsuka Pharmaceutical Factory, Inc., Naruto, Tokushima 772-8601, Japan \\ \#Sekisui Medical Co., Chuo-ku, Tokyo 103-0027, Japan \\ SDrug Discovery and Development Institute, Tsukuba, Ibaragi 305-0036, Japan \\ IGraduate School of Engineering, Nagoya Institute of Technology, Showa-ku, Nagoya 466-8555, \\ Japan
}

-Department of Biochemistry, Vanderbilt University School of Medicine, Nashville, Tennessee, United States 37232-0146

\begin{abstract}
Bioactivation of 5-hydroxy- $\left[\right.$ carbonyl $\left.-{ }^{14} \mathrm{C}\right]$ thalidomide, a known metabolite of thalidomide, by human artificial or native cytochrome $\mathrm{P} 4503 \mathrm{~A}$ enzymes, and nonspecific binding in livers of mice was assessed using two-dimensional electrophoresis combined with accelerator mass spectrometry. The apparent major target proteins were liver microsomal cytochrome $c$ oxidase subunit 6B1 and ATP synthase subunit $a$ in mice containing humanized $P 4503 A$ genes or transplanted humanized liver. Liver cytosolic retinal dehydrogenase 1 and glutathione transferase
\end{abstract}

\footnotetext{
*Corresponding Author. (H.Y.) Showa Pharmaceutical University, 3-3165 Higashitamagawa Gakuen, Machida, Tokyo 194-8543, Japan. Telephone: +81-42-721-1406; FAX: +81-42-721-1406. hyamazak@ac.shoyaku.ac.jp.

ASSOCIATED CONTENT

Supporting Information. Experimental Procedures, Table S1 (microsomal proteins bound with radiolabeled 5-hydroxythalidomide in increasing order of spot ID numbers), Table S2 (cytosolic proteins bound with radiolabeled 5-hydroxythalidomide in increasing order of spot ID numbers), Figure S1 (chemical structure of 5-hydroxy-[ carbonyl- $\left.{ }^{14} \mathrm{C}\right]$ thalidomide), Figure S2 (two-dimensional electrophoretic profiles of liver microsomal protein fractions obtained from mice with humanized $C Y P 3 A$-HAC and with humanized liver $1 \mathrm{~h}$ after intravenous administration of radiolabeled 5-hydroxythalidomide), Figure S3 (two-dimensional electrophoretic profiles of liver cytosolic protein fractions obtained from mice with humanized CYP3A-HAC (A) and with humanized liver $1 \mathrm{~h}$ after intravenous administration of radiolabeled 5-hydroxythalidomide), Figure S4 (two-dimensional electrophoresis of pooled fetal homogenates obtained from mice with humanized $C Y P 3 A$-HAC, treated intravenously with 5-hydroxythalidomide). This material is available free of charge via the Internet at http://pubs.acs.org.
} 
A1 were targets in humanized mice with P450 3A and hepatocytes. 5-Hydroxythalidomide is bioactivated by human P450 3A enzymes and trapped with proteins nonspecifically in humanized mice.

\section{Graphical Abstract}

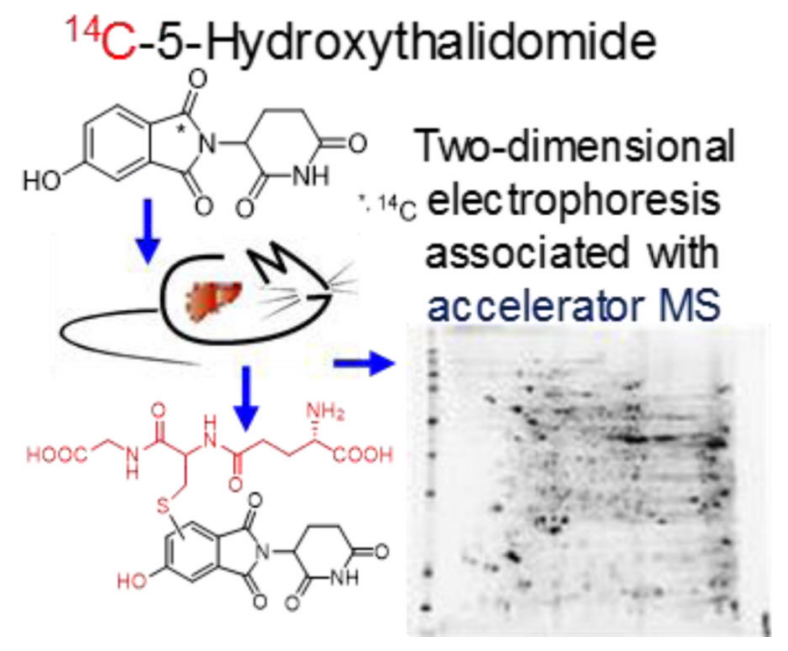

The metabolism of thalidomide is important for both teratogenicity and anticancer efficacy. ${ }^{1}$ Recently, a whole-embryo culture system from transchromosomic mice containing a human cytochrome $\mathrm{P} 4503 \mathrm{~A} \mathrm{cluster}^{2}$ (in which the endogenous mouse Cyp3a genes were deleted) showed limb abnormalities. ${ }^{3}$ It was demonstrated that human P450s 3A4 and 3A5 can also oxidize thalidomide to primary 5 -hydroxy- and secondary dihydroxy metabolites ${ }^{4-7}$ in mice with highly "humanized" liver cells. ${ }^{8}$ This finding would suggest generation of a putative reactive arene oxide ${ }^{1}$ in the oxidation of 5 -hydroxy thalidomide, trapped by GSH to give GSH adducts. Determining if covalent protein binding of thalidomideoccurs and whether the primary metabolites are bound to specific proteins ${ }^{9,10}$ or not can be important in evaluating toxic and pharmacological potential. Because the secondary oxidation of 5hydoxythalidomide was noted to be faster than the primary thalidomide 5-hydoxylation mediated by recombinant human $\mathrm{P} 4503 \mathrm{~A} 4 / 5,{ }^{7}$ the in vivo metabolic activation a primary metabolite of thalidomide was investigated after administration of radiolabeled compound to two humanized model mice in this study. One mouse had fully humanized $C Y P 3 A$ gene ${ }^{2}$ (designated P450 3A-human artificial chromosome (HAC)/Cyp3a knock-out (KO)) and the other was a mouse with highly humanized liver cells harboring cytochrome $C Y P 3 A 5^{*} 1{ }^{8}$ Both humanized $C Y P 3 A-\mathrm{HAC} /$ Сур3а KO mice ${ }^{5}$ and humanized TK-NOG mice ${ }^{11}$ were previously confirmed to have adequate human P450 3A enzyme levels and activities. We report herein that analyses using two-dimensional electrophoresis with accelerator mass spectrometry revealed that in vivo bioactivated 5-hydroxythalidomide bound nonspecifically to a variety of microsomal and cytosolic proteins in livers in mice with humanized $C Y P 3 A$ gene or with transplanted humanized liver.

Mean concentrations of radiolabeled 5-hydroxythalidomide in plasma, livers, and fetal samples were $0.64 \pm 0.25 \mu \mathrm{g}$ equivalent $/ \mathrm{mL}$ (mean $\pm \mathrm{SD}, \mathrm{n}=5$ ), $1.4 \pm 1.0 \mu \mathrm{g}$ equivalent $/ \mathrm{g}$ liver, and $0.06 \pm 0.04 \mu \mathrm{g}$ equivalent/g fetus, respectively, $1 \mathrm{~h}$ after i.v. administration in 
female mice containing humanized $C Y P 3 A$ gene. Similarly, mean concentrations of radiolabeled 5-hydroxyhtalidomide in plasma and livers were $0.50 \pm 0.14 \mu \mathrm{g}$ equivalent $/ \mathrm{mL}$ (mean $\pm \mathrm{SD}, \mathrm{n}=5$ ) and $0.43 \pm 0.09 \mu \mathrm{g}$ equivalent/g liver $1 \mathrm{~h}$ after i.v. administration in male mice with humanized liver, respectively: the mean plasma concentration of 5-

hydroxythalidomide determined by LC-MS/MS was $5.5 \pm 1.2 \mathrm{ng} / \mathrm{mL}$, implying extensive metabolism of 5-hydroxythalidomide in humanized liver mice.

Profiles of liver microsomal and cytosolic fractions were investigated by two-dimensional electrophoresis in livers of mice containing humanized $C Y P 3 A$ gene or with transplanted humanized liver $1 \mathrm{~h}$ after the administration of radiolabeled 5-hydroxythalidomide. Protein samples $(100 \mu \mathrm{g})$ were separated by isoelectric point ( $\mathrm{pH} 3-10)$ and molecular weight (10$225 \mathrm{kDa})$; two-dimensional electrophoresis $(20 \mathrm{~cm} \times 20 \mathrm{~cm})$ revealed a variety of liver microsomal (Supporting Information Figure S2) and cytosolic (Supporting Information Figure S3) proteins. The most abundant protein spots (in two-dimensional gels from livers of mice with humanized $C Y P 3 A$ genes and with transplanted humanized liver) were selected and analyzed for radioactivity incorporated from 5-hydroxythalidomide. Consequently, nine target protein spots related to 5-hydroxythalidomide exposure were chosen for both microsomal and cytosolic protein (Figure 1). Target protein contents and covalent binding contents of these analyte spots in the gels are summarized in Table S1 (Supporting Information). The apparently highest covalent binding content (in terms of pmol equivalent/ $\mu \mathrm{g}$ target protein) was seen in liver microsomal cytochrome $c$ oxidase subunit 6B1 (NCBI accession number gi:3023546) and ATP synthase subunit a (gi:416677) in mice with humanized $C Y P 3 A$-HAC and with humanized liver mice (Table S1), respectively. On the other hand, retinal dehydrogenase 1 (gi:194375548) and GSH transferase (GST) A1 (gi: 121730) showed the highest covalent binding content (in terms of pmol equivalent/ $\mu \mathrm{g}$ target protein) in the liver cytosol fractions in mice with humanized $C Y P 3 A-\mathrm{HAC}$ and with humanized liver mice, respectively, after two-dimensional electrophoresis and accelerator mass spectrometry (Table S2, Supporting Information). It is possible that every spot in the 2D-gels $(20 \mathrm{~cm} \times 20 \mathrm{~cm})$ could potentially contain multiple proteins but that only the major one might have been detected under the current protein analysis system. Two-dimensional electrophoresis of pooled fetal homogenate samples (11.5 days), with one-tenth radioactivity of liver samples, was also carried out (Supporting Information Figure S4). However, the database software for peptide identification did not have sufficient mouse fetal protein information, and further analysis for protein identification and/or radioactivity determination was not possible. Rough linearity between covalent binding content and proposed target protein concentration was seen in the case of 5-hydroxythalidomide (Figure 1). The estimated covalent binding levels (pmol drug equivalent/ $\mu$ g target protein) indicate an inverse relationship with target protein concentration under the present conditions.

The mechanism of action and teratogenicity of thalidomide still remains unclear, but a ubiquitously expressed ligase protein, cereblon, has been reportedly identified as a primary teratogenic target of thalidomide, lenalidomide, and pomalidomide, using modified chemical probes located at an aromatic position, in conjunction with ferric beads. ${ }^{12,13}$ Unlike some of the binding proteins for radiolabeled troglitazone and flutamide (reported previously), ${ }^{9}, 10$ few proteins with high covalent binding content and high target protein concentration were observed (Figure 1). Under the electrophoretic conditions used here, cereblon would be 
expected to be found in an area defined by an isoelectric point of $\mathrm{pH} 4.5-5.5$ and a molecular weight of 48-60 kDa (UniProt accession numbers, Q96SW2 and Q8C7D2); however, there were no large protein spots in this study. Selenium binding protein 1 (56 kDa, acetaminophen binding protein, gi: 16306550), suggested in previous studies with troglitazone and 5-n-butyl-pyrazolo[1,5-a]pyrimidine, ${ }^{9,10}$ was not detected in the case of 5hydroxythalidomide. In the future, immunoprecipitation experiments with specific antibodies against cereblon or selenium binding protein 1 might be helpful in understanding the roles of these proteins in trapping activated 5-hydroxythalidomide or its further metabolites. Although GST A1 has been ranked as a minor target binding protein with trogltazone, ${ }^{9,10}$ GST A1 appeared to be one of more important enzymes trapping the activated 5-hydroxythalidomide in both humanized mouse models (Table S2), perhaps because of its abundance or its ability to bind hydrophobic chemicals (originally defined as a "ligandin"14). Another proteomics analysis has reported on thalidomide embryotoxicity using differentiation of human embryonic stem cells, and one novel possible mechanism involved inhibition of GST A1. ${ }^{15}$ Some of target liver proteins detected in this studycytochrome $c$ oxidase subunit $6 \mathrm{~B} 1$, cytochrome $b$-c1 complex subunit 7 , and ATP synthase subunit a (Table S1) — have been reported to be involved in protein-protein interaction networking ${ }^{16,17}$ and associated with Leigh syndrome caused by aspirin use, but only in children. ${ }^{18}$ Cytochrome $c$ oxidase subunit $6 \mathrm{~A} 1$ has been associated with Charcot-MarieTooth neuropathy disease, which causes nerve damage (mostly in the arms and legs). ${ }^{19}$

Apparently different target proteins for 5-hydroxythalidomide were seen in liver microsomal and cytosolic fractions in both female and male mice with humanized $C Y P 3 A$-HAC and humanized liver in the present study. Intravenously administered 5-hydroxythalidomide was further bioactivated by human P450 3A enzymes in vivo and trapped with nonspecific proteins in humanized mouse models with $\mathrm{P} 4503 \mathrm{~A}$ or hepatocytes. Aromatic hydroxylation of 5-hydroxythalidomide occurred in humanized mice models one hour after i.v. administration: however, this reactive secondary metabolite(s) is nonspecifically trapped. In the case of future treatments with GSH- depleting agents, abundant protein adducts might be analyzed with potential importance of the secondary metabolism of 5-hydroxythalidomide in thalidomide toxicity in pregnant mice. Thalidomide could exert its variety of pharmacological and toxic actions through multiple mechanisms including non-specific modification of many protein networks after bioactivation by human P450 enzymes.

\section{Supplementary Material}

Refer to Web version on PubMed Central for supplementary material.

\section{Acknowledgments}

Funding Sources

This work was supported in part by the Japan Society for the Promotion of Science Grants-in-Aid for Scientific Research 26460206 (H.Y.), the JCIA LRI program, the MEXT (Ministry of Education, Science, Sports, and Culture of Japan)-Supported Program for the Strategic Research Foundation at Private Universities, 2013-2018 and National Institutes of Health grants R37 CA090426 and R01 GM118122 (F.P.G.).

The authors thank Drs. Takao Matsui, Norie Murayama, and Shotaro Uehara for their technical assistance. 
ABBREVIATIONS
CYP
P450 gene
GST GSH transferase
HAC human artificial chromosome
HSVtk herpes simplex virus type 1 thymidine kinase
NOG mice non-obese diabetes- severe combined immunodeficiency- interleukin-2 receptor gamma chain-deficient mice

\section{REFERENCES}

1. Gordon GB, Spielberg SP, Blake DA, Balasubramanian V. Thalidomide teratogenesis: evidence for a toxic arene oxide metabolite. Proc. Natl. Acad. Sci. U. S. A. 1981; 78:2545-2548. [PubMed: 6941308]

2. Kazuki Y, Kobayashi K, Aueviriyavit S, Oshima T, Kuroiwa Y, Tsukazaki Y, Senda N, Kawakami H, Ohtsuki S, Abe S, Takiguchi M, Hoshiya H, Kajitani N, Takehara S, Kubo K, Terasaki T, Chiba K, Tomizuka K, Oshimura M. Trans-chromosomic mice containing a human CYP3A cluster for prediction of xenobiotic metabolism in humans. Hum. Mol. Genet. 2013; 22:578-592. [PubMed: 23125282]

3. Kazuki Y, Akita M, Kobayashi K, Osaki M, Satoh D, Abe S, Takehara S, Kazuki K, Yamazaki H, Kamataki T, Oshimura M. Thalidomide-induced limb abnormalities in a humanized CYP3A mouse model. Sci. Rep. 2016; 6:21419. [PubMed: 26903378]

4. Yamazaki H, Suemizu H, Igaya S, Shimizu M, Shibata M, Nakamura M, Chowdhury G, Guengerich FP. In vivo formation of a glutathione conjugate derived from thalidomide in humanized uPA-NOG mice. Chem. Res. Toxicol. 2011; 24:287-289. [PubMed: 21299192]

5. Yamazaki H, Suemizu H, Shimizu M, Igaya S, Shibata N, Nakamura N, Chowdhury G, Guengerich FP. In vivo formation of dihydroxylated and glutathione conjugate metabolites derived from thalidomide and 5-hydroxythalidomide in humanized TK-NOG mice. Chem. Res. Toxicol. 2012; 25:274-276. [PubMed: 22268628]

6. Chowdhury G, Shibata N, Yamazaki H, Guengerich FP. Human cytochrome P450 oxidation of 5hydroxythalidomide and pomalidomide, an amino analog of thalidomide. Chem. Res. Toxicol. 2014; 27:147-156. [PubMed: 24350712]

7. Chowdhury G, Murayama N, Okada Y, Uno Y, Shimizu M, Shibata N, Guengerich FP, Yamazaki H. Human liver microsomal cytochrome P450 3A enzymes involved in thalidomide 5-hydroxylation and formation of a glutathione conjugate. Chem. Res. Toxicol. 2010; 23:1018-1024. [PubMed: 20443640]

8. Nishiyama S, Suemizu H, Shibata N, Guengerich FP, Yamazaki H. Simulation of human plasma concentrations of thalidomide and primary 5-hydroxylated metabolites explored with pharmacokinetic data in humanized TK-NOG mice. Chem. Res. Toxicol. 2015; 28:2088-2090. [PubMed: 26492539]

9. Yamazaki H, Kuribayashi S, Inoue T, Tateno C, Nishikura Y, Oofusa K, Harada D, Naito S, Horie T, Ohta S. Approach for in vivo protein bindings of 5-n-butyl-pyrazolo[1,5-a]pyrimidine bioactivated in chimeric mice with humanized liver by two-dimensional electrophoresis with accelerator mass spectrometry. Chem. Res. Toxicol. 2010; 23:152-158. [PubMed: 19928966]

10. Yamazaki H, Kuribayashi S, Inoue T, Honda T, Tateno C, Oofusa K, Ninomiya S, Ikeda T, Izumi T, Horie T. Zone analysis by two-dimensional electrophoresis with accelerator mass spectrometry of in vivo protein bindings of idiosyncratic hepatotoxicants troglitazone and flutamide bioactivated in chimeric mice with humanized liver. Toxicol. Res. 2015; 4:106-111. 
11. Hasegawa M, Kawai K, Mitsui T, Taniguchi K, Monnai M, Wakui M, Ito M, Suematsu M, Peltz G, Nakamura M, Suemizu H. The reconstituted 'humanized liver' in TK-NOG mice is mature and functional. Biochem. Biophys. Res. Commun. 2011; 405:405-410. [PubMed: 21238430]

12. Ito T, Ando H, Suzuki T, Ogura T, Hotta K, Imamura Y, Yamaguchi Y, Handa H. Identification of a primary target of thalidomide teratogenicity. Science. 2010; 327:1345-1350. [PubMed: 20223979]

13. Lopez-Girona A, Mendy D, Ito T, Miller K, Gandhi AK, Kang J, Karasawa S, Carmel G, Jackson P, Abbasian M, Mahmoudi A, Cathers B, Rychak E, Gaidarova S, Chen R, Schafer PH, Handa H, Daniel TO, Evans JF, Chopra R. Cereblon is a direct protein target for immunomodulatory and antiproliferative activities of lenalidomide and pomalidomide. Leukemia. 2012; 26:2326-2335. [PubMed: 22552008]

14. Habig WH, Pabst MJ, Fleischner G, Gatmaitan Z, Arias IM, Jakoby WB. The identity of glutathione S-transferase B with ligandin, a major binding protein of liver. Proc. Natl. Acad. Sci. U. S. A. 1974; 71:3879-3882. [PubMed: 4139704]

15. Meganathan K, Jagtap S, Wagh V, Winkler J, Gaspar JA, Hildebrand D, Trusch M, Lehmann K, Hescheler J, Schluter H, Sachinidis A. Identification of thalidomide-specific transcriptomics and proteomics signatures during differentiation of human embryonic stem cells. PLoS One. 2012; 7:e44228. [PubMed: 22952932]

16. The UniProt Consortium. UniProt: a hub for protein information. Nucleic Acids Res. 2015; 43:D204-D212. [PubMed: 25348405]

17. Szklarczyk D, Franceschini A, Wyder S, Forslund K, Heller D, Huerta-Cepas J, Simonovic M, Roth A, Santos A, Tsafou KP, Kuhn M, Bork P, Jensen LJ, von MC. STRING v10: protein-protein interaction networks, integrated over the tree of life. Nucleic Acids Res. 2015; 43:D447-D452. [PubMed: 25352553]

18. Massa V, Fernandez-Vizarra E, Alshahwan S, Bakhsh E, Goffrini P, Ferrero I, Mereghetti P, D'Adamo P, Gasparini P, Zeviani M. Severe infantile encephalomyopathy caused by a mutation in COX6B1, a nucleus-encoded subunit of cytochrome $c$ oxidase. Am. J. Hum. Genet. 2008; 82:1281-1289. [PubMed: 18499082]

19. Tamiya G, Makino S, Hayashi M, Abe A, Numakura C, Ueki M, Tanaka A, Ito C, Toshimori K, Ogawa N, Terashima T, Maegawa H, Yanagisawa D, Tooyama I, Tada M, Onodera O, Hayasaka K. A mutation of COX6A1 causes a recessive axonal or mixed form of Charcot-Marie-Tooth disease. Am. J Hum. Genet. 2014; 95:294-300. [PubMed: 25152455] 


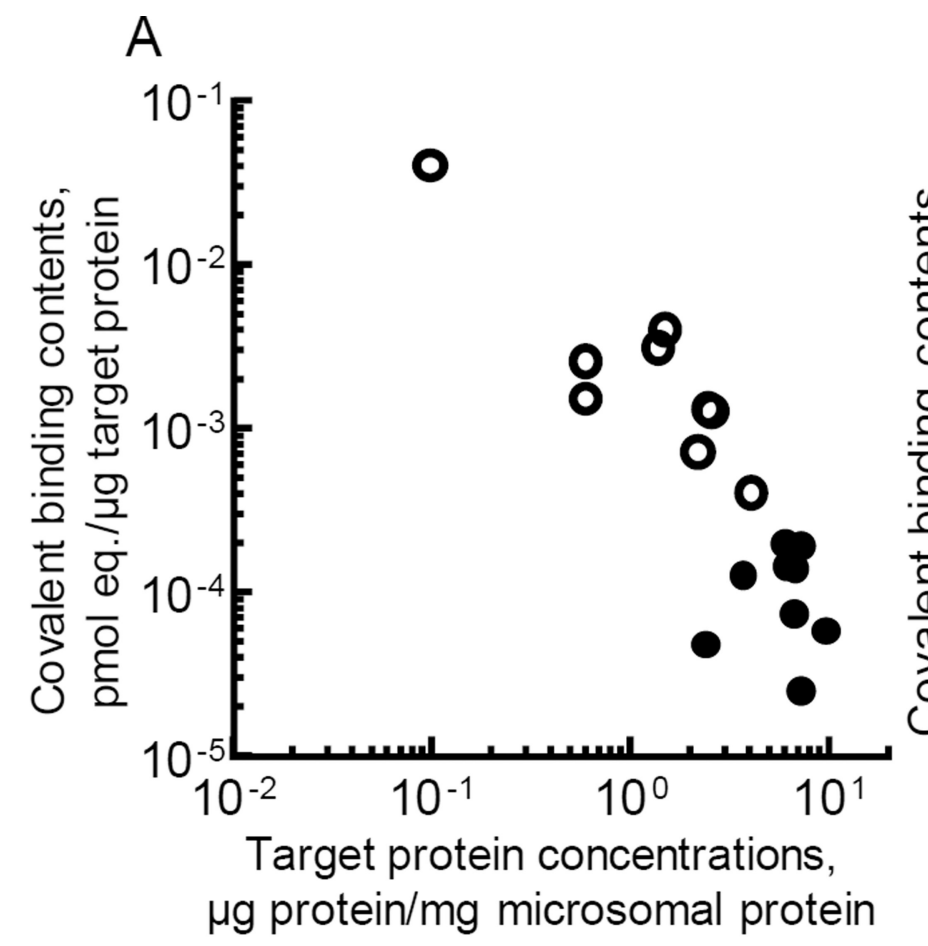

B

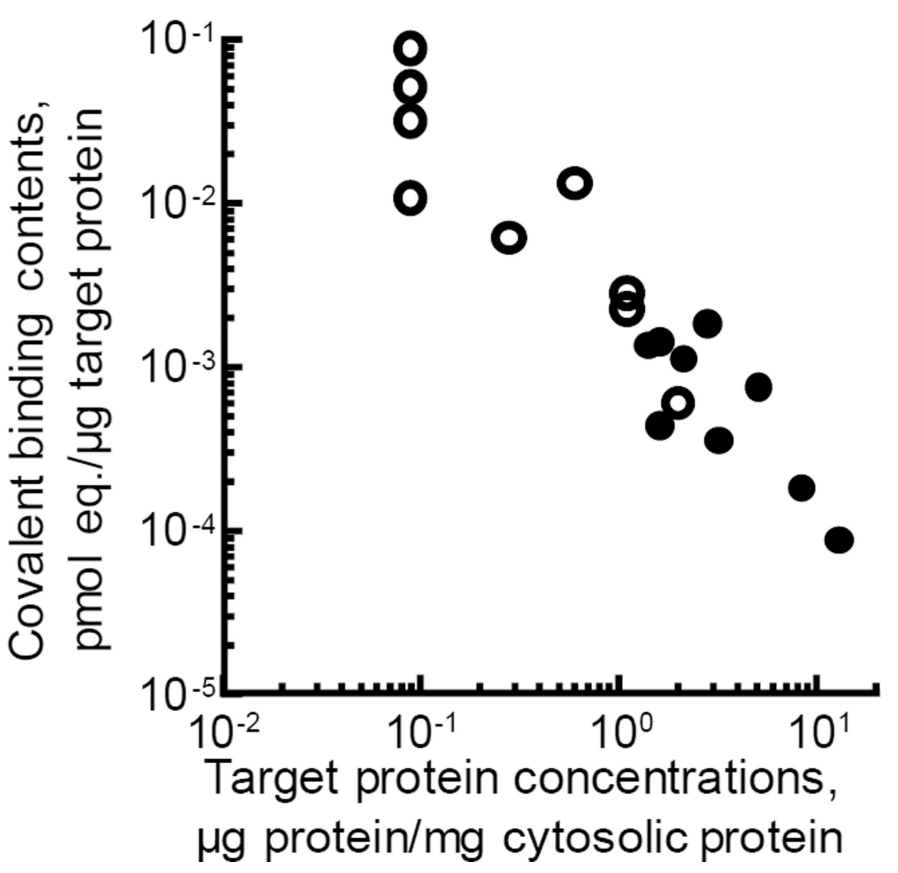

Figure 1.

In vivo protein binding profiles of liver microsomal (A) and cytosolic (B) fractions derived from metabolically activated 5-hydroxy- $\left[{ }^{14} \mathrm{C}\right]$-thalidomide in mice with humanized $C Y P 3 A$ HAC (open circles) and with humanized liver (closed circles) analyzed by two-dimensional electrophoresis and accelerator mass spectrometry. 